\title{
APPLICATION OF MODERN MEASUREMENT TECHNIQUES FOR ANALYSIS OF INJECTION MOULDING SHRINKAGE
}

\author{
Jerzy Jozwik ${ }^{1}$, Arkadiusz Tofil ${ }^{2}$, Andrzej Lukaszewicz ${ }^{3}$ \\ ${ }^{1}$ Lublin University of Technology, Poland; ${ }^{2}$ The State School of Higher Education in Chelm, Poland; \\ ${ }^{3}$ Bialystok University of Technology, Poland \\ j.jozwik@pollub.pl, atofil@pwsz.chelm.pl, a.lukaszewicz@pb.edu.pl
}

\begin{abstract}
The process of polymer injection moulding is complex and complicated, therefore it is characterised by a number of technological and material parametersthat influence the product quality. Setting the best injection conditions requires knowledge of the processing properties of the material, mould shape and technological capacity of the injection moulding machine. Injection shrinkage, as undesirable phenomenon, causes changes of the shape and dimensions of the injection moulding; therefore, it is one of the most important problems that have to be solved, both at the phase of mould designing and at selecting the technological parameters of injection. The paper presents classification of injection moulding shrinkage as well as factors influencing the value of the shrinkage. The conducted experimental tests were related to selected topics connected with the injection process and took into account the change of the processed material characteristics (type and amount of filler) and change of certain, relatively the simplest to regulate, injecting parameters (injection time and cooling of the piece in a mould). Geometrical dimensions of the injection mouldings produced from polypropylene filled with glass fibre were measured using two methods: tactile (electronic measuring instrument) and contactless (3D scanning). The analysis of injection shrinkage illustrates that an effective influence on its value is possible by both choosing appropriate conditions of the injection within the technical range of the machine, as well as, if needed, the processing properties of material can be modified in order to obtain a moulded piece of set geometrical and strength properties. After the analysis of the results, the connection between the injection moulding shrinkage and the content of the filler and the chosen parameters of injection was established.
\end{abstract}

Keywords: injection moulding, shrinkage, filler, measurement techniques, 3D scanning.

\section{Introduction}

The injection moulding process is the most commonly used method of manufacturing plastic parts. There are different forms of injection and periodicity is its characteristics. Injection is used for processing almost all polymer materials, especially thermo-plastic and thermo-setting plastics, as well as rubber compounds, liquid silicon and composites. The result of injection is an injection molded part, which depending on the type of injection and the material used, has a wide range of application possibilities, variety of shape, manufacturing accuracy and endurance properties [1-4]. Shrinkage is an extremely important parameter that must be taken into account during injection moulding, because it affects the structural features determined by the shape and dimensions of the moulded part. It also determines the applicability and aesthetic features of the plastic product [5-7].

The process of injection moulding design is determined by the type of material, the injection method used and its technological conditions, as well as the injection form structure and facilities of the injection moulding machine. These factors influence directly or indirectly final dimensions, the structure and the shape of the moulded piece, in accordance with the specification range established in the construction process and the processing anomalies (material and surface), essential from the point of view of the user [8-9].Processing shrinkage depends on many factors, which can be grouped as follows $[2 ; 5 ; 7]$ :

- material - density, molecular weight, crystalline or amorphous structure, amount of filler,

- product - shape, dimensions, dimensional accuracy and the specification range,

- structure of the tool - runner system, shape of the cavity,

- processing conditions - material and mould temperature, product cooling parameters.

Figure 1 presents schematic influence of the chosen factors on the processing shrinkage of polymer materials. Materials of greater density show greater processing shrinkage. Materials of lower density crystallise a little less because of their greater chain branching, which leads to smaller shrinkage. Processing shrinkage decreases together with an increase of the mass melt flow index [5;7]. It is known that crystalline materials have greater processing shrinkage than amorphous materials [56,8].The shrinkage process should be identified on the basis of measurements of standardized samples in the form of a dog-bone shaped specimen. 


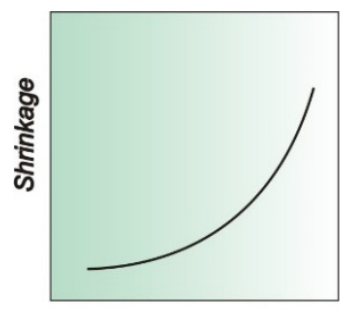

Melt temperature

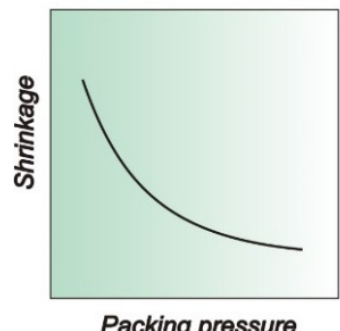

Packing pressure

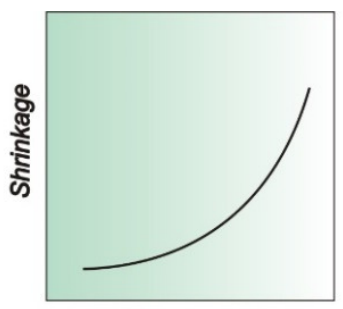

Mold temperature

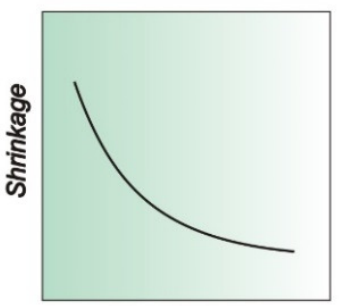

Packing time

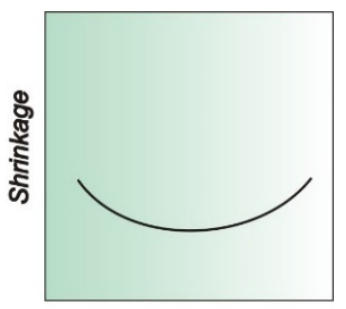

Injection rate

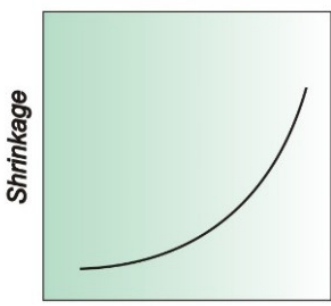

Part thickness

Fig. 1. Influence of chosen factors on processing shrinkage of polymer materials [5]

Fillers, as supplementary substances, are added to the material at various stages of its processing, therefore they have distinctive influence on the change of the properties of the obtained products and the course of the process itself. With regards to the injection process, fillers - both as powder and as short fibres show positive effect causing the decrease of the injection shrinkage and dimensional stabilisation of the piece. In case of fibrous fillers, depending on the injection conditions and plastic part shape, there may occur clear orientation of the fibres, which results in anisotropic shrinkage. However, addition of fillers causes wear of the injection moulding machine by abrasive erosion of the cylinder and the screw. What is more, some fillers decrease the rheological properties of the material, inhibiting its flow [3;10-11]. Anisotropic shrinkage of materials without fillers is relatively small, especially for amorphous materials. Anisotropy of filled materials depends mainly on the amount and shape of fillers, the shape and dimensions of the piece, the method of bringing the material to the cavity (connected with filling of the cavity and filler orientation), as well as on the dimensions and shape of the gate [12-13].

The technology of the tool and die manufacturing in the plastic injection branch is one of the world's fastest growing industries [14-15]. The CAx (CAD/CAM/CAE etc.) techniques are widely used in the mechanical engineering field [16-19]. The main reason of using CAx tools is primarily reduction time-to-market of new product. CAE analyses [20-24], CAM and CNC manufacturing techniques [25-28] allow to faster and better fit of the design assumptions. The Reverse Engineering (RE) methods can be used to accurately reproduce free-form shapes using non-contact [29] and contact [30] measurement techniques. Today mold design requires a complex CAx system with simulation of the injection process [31-32]. This software allows predicting of defects in early stage of the plastic part design and their elimination [33-34].

\section{Materials and methods}

For experimental tests, enabling evaluation of the influence of the type and amounts of the filler and the chosen parameters of the injection process on the value of the linear shrinkage, the injection moulds in the shape of tensile test samples were used. The samples were manufactured using a laboratory screw injection moulding machine, with the variable parameters: the filling time (4 s, $6 \mathrm{~s})$ and the cooling time of the piece in the mould (15 s, $30 \mathrm{~s}$ and 45 s). Polypropylene Moplen EP440G produced by Lyondell Basell consortium was used as plastic material. For the filler, the short glass fibre and talc prepared as ready concentrates were used. For injecting the portions of material of respectively $10 \%, 20 \%, 30 \%$ and $40 \%$ particular filler amounts were prepared, as well as polypropylene without the filler. The temperature in particular heating zones of the moulding machine plasticising system changed in the range from $220^{\circ} \mathrm{C}$ to $240{ }^{\circ} \mathrm{C}$ and the temperature in the nozzle was $245^{\circ} \mathrm{C}$. The tool was the two-cavity injection mould. Inlet channels have been constant temperature $50{ }^{\circ} \mathrm{C}$. The dimensions of the mould cavity were: length $L=152.00 \mathrm{~mm}$, height $H=20.15 \mathrm{~mm}$ and thickness $B=4.00 \mathrm{~mm}$. Measurements of the geometrical dimensions of the pieces from particular 
series differing in the type and filler amount, achieved with various injection parameters, were conducted by two methods: tactile and contactless. While using the first of them, the pieces were measured to an accuracy of $0.01 \mathrm{~mm}$ with an electronic measuring instrument (EMI), and in the second method particular samples were scanned with the use of 3D ATOS COMPACT SCAN produced by GOM company. ATOS 3D scanner is a non-contact measurement system using the optical triangulation method. For analysing secondary shrinkage (after 16 hours of the end of the injection process), measurements of the specimen length $\mathrm{L}$ were used in order to set the longitudinal shrinkage; and the results of the height of the piece $\mathrm{H}$ in order to set the perpendicular shrinkage. In case of measurements conducted with the use of the electronic slide calliper, particular values of shrinkage were set according to appropriate dimensions of the mould cavity by using common mathematical dependencies presented in literature [5-6;12]. According to the measurements of the shape and dimensions of the injection mouldings carried outusing the 3D scanner, particular values of the shrinkage were based on comparing the results of the 3D scanning associated with the digital solid model of the injection moulding. Taking into account the linear expansion of the mold due to temperature, additionally shrinkage of the mould has been corrected automatically by software.

\section{Results and discussion}

A basic form of presentation of the results after the scanning process is a colour map of the deviations [35]. It can be generated only when a CAD model is applied to a scanned element. If this condition is met, by the CAD model applied on the STL net points, the colour visualisation of the deviation maps is obtained. Figure 2 shows a 3D model of an actual moulded piece with a solid model of ideal moulded piece applied, together with the map of deviations between the surfaces.

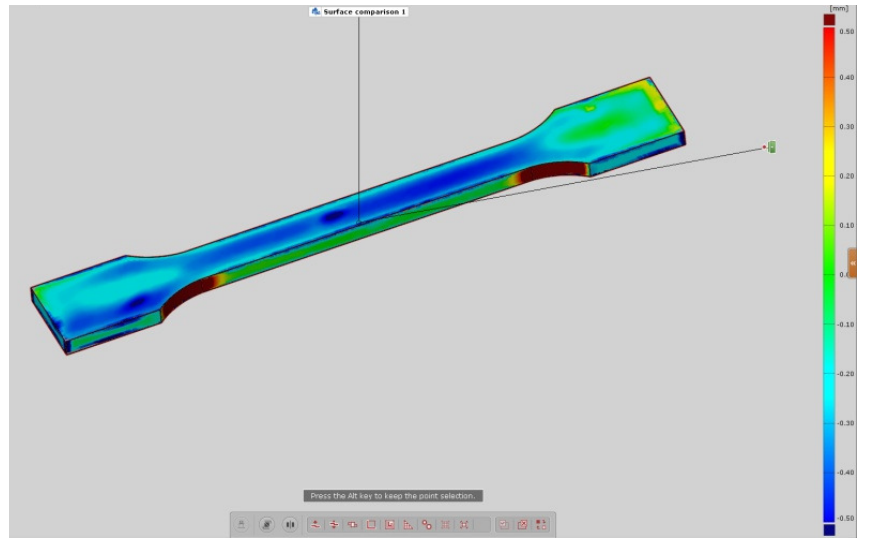

Fig. 2. 3D actual moulded piece with solid model applied to it, including map of deviations

Figure 3 presents compilation of the value of longitudinal shrinkage set based on the measurements with the use of EMI, depending on the time of the filling phase and the cooling time of the piece in the mould depending on varying amounts of glass fibre and talc.

Figure 4 shows examples of the geometrical dimension measurements achieved by the use of GOM Inspect Professional V8 software of the 3D scanner. The differences in the value of processing shrinkage set on the basis of the geometrical dimensions of the moulded piece measurements conducted with the use of the GOM scanner and with the use of the electronic measurement instrument (EMI) were between 5 and $10 \%$; only in the case of pieces produced from polypropylene with 30 and $40 \%$ of glass fibre in the filling phase lasting $4 \mathrm{~s}$ and the cooling time of $30 \mathrm{~s}$, the difference amounted to almost $15 \%$.

An example of dependence between processing shrinkage and the amount of filler set on the basis of two different measurement methods of the geometrical dimensions of pieces is presented in Figure 5, where the filler was glass fibre, injection time was $4 \mathrm{~s}$, and the cooling time was $15 \mathrm{~s}$. Irrespective of small differences in the value of the injection shrinkage (difference of linear dimensions), derived from the results of the measurements by the two presented methods, it was stated that the increase of the amount of filler resulted in lower values of shrinkage. This influence was especially visible in the case of glass fibre, where the shrinkage decreased twice in comparison to the shrinkage of the piece without filler. 
a)

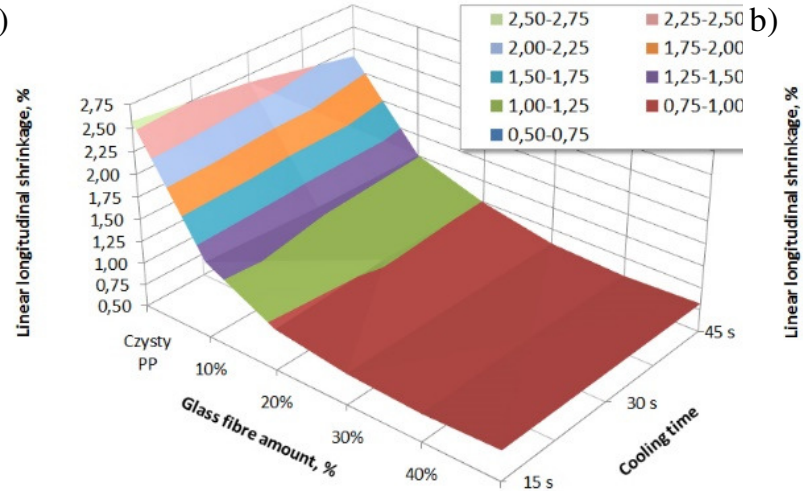

$50 \%$

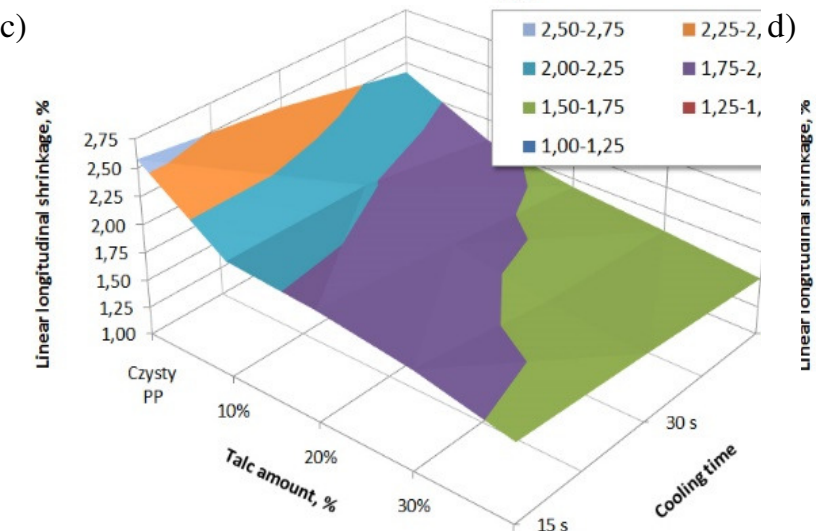

$40 \%$
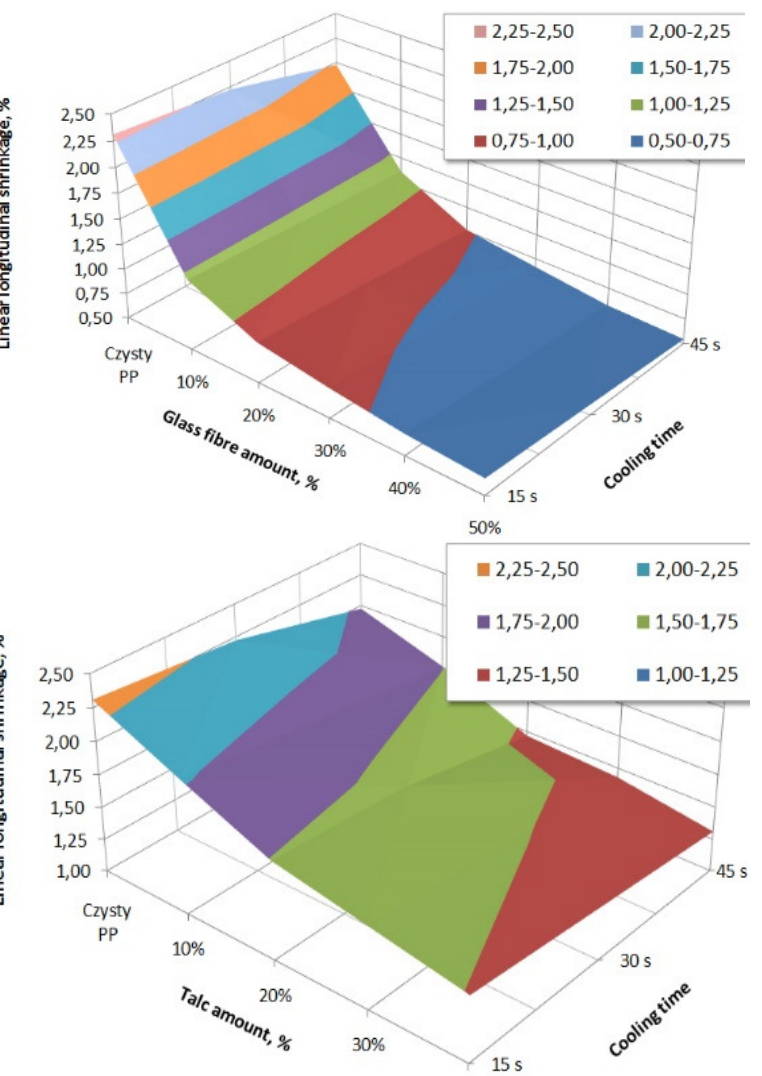

$40 \%$

Fig. 3. Dependence of longitudinal shrinkage on amount of filler and time of moulded piece cooling: a, c-injection time $4 \mathrm{~s} ; \mathrm{b}, \mathrm{d}$-injection time $6 \mathrm{~s}$

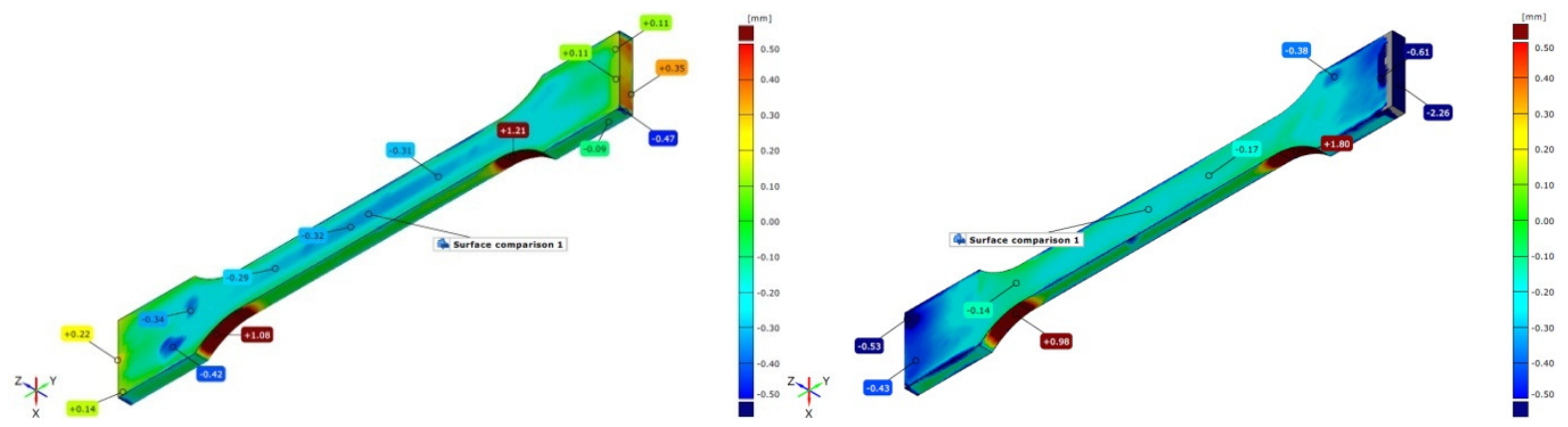

Fig. 4. Examples of geometrical measurements using GOM Inspect Professional V8 software

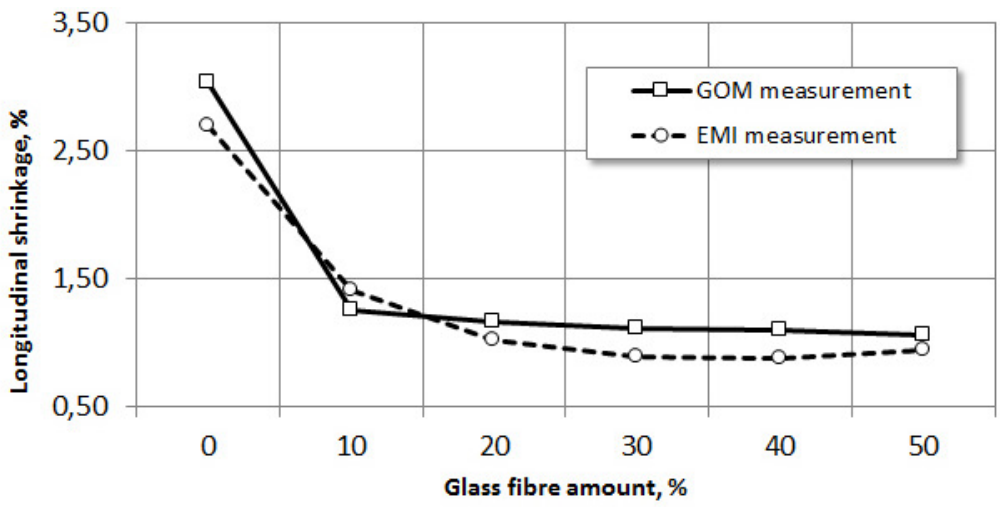

Fig. 5. Differences between amount of filler and processing shrinkage based on two various methods of geometrical dimension measurements: tactile (EMI) and contactless (GOM) 
Addition of talc decreased the value of shrinkage, but not as much as glass fibre. In the case of glass fibre the decrease of shrinkage was visible during the change of filler from $10 \%$ to $20 \%$ and then to $30 \%$. Further increase of the percentage amount of glass fibre in polypropylene did not cause visible decrease of shrinkage. In the case of talc filler, the decrease of the shrinkage value was not as big as in the case of glass fibre and took place regularly with increasing the amount of talc in the material.

\section{Conclusions}

The process of polymer injection moulding is complex, therefore, it is characterised by a number of factors. The factors cause that setting the best injection conditions requires knowledge of the processing properties of the material, mould geometrical characteristics and the technological capacity of the injection moulding machine. The performed experimental tests related to selected topics connected with the injection process and took into account the change of the processed material characteristics (type and amount of filler) and change of certain, relatively the simplest to regulate, injecting parameters (injection and cooling time of the part in a mould).Injection shrinkage causes change of the shape and dimensions of the injection moulded parts, therefore, it is one of the most important problems that have to be solved, both at the phase of mould designing and at selecting the technological parameters of injection.

The analysis of injection shrinkage illustrates that an effective influence on its value is possible by both choosing the appropriate conditions of injection within the technical range of the machine, as well as, if needed, the processing properties of the material can be modified in order to obtain a moulded product with proper geometrical and strength properties. Increasing the amount of filler in the matrix and extending the injection time significantly reduces the value of injection shrinkage. This improves the dimensional accuracy of the manufactured parts and reduces the number of bad products. Measurements and estimation of geometric conformity of an actual object with the digital model might be conducted by tactile and contactless methods. The tactile methods based on measurement machines and mobile systems are time-consuming and need qualified operating staff. Contactless methods, including 3D optic measurement, are an alternative. High quality of data, a number of measurement points providing information about the surface of the measured element and the direct comparison with CAD data are the main advantages when choosing the optical method. Optical measurement can be effectively used to object dimensioning where other techniques are ineffective or their usage is complex, time-consuming and problematic.

\section{References}

[1] Bociąga E. Specjalne metody wtryskiwania tworzy w polimerowych (Special methods for injection of polymer materials). Warszawa, WNT, 2008. 210 p. (In Polish)

[2] Rosato D.V., Rosato M.G. Injection Molding Handbook. 3rd edition, Norwell, Kluwer Academic Publisher, 2000. 1640 p.

[3] Suberlyak O., Krasinskyi V., Moravskyi V., GerlachH., Jachowicz T. Influence of aluminosilicate filler on the physicomechanical properties of polypropylene-polycaproamide composites. Materials Science, vol. 50, issue 2, 2014, pp. 296-302.

[4] Yang S.S., Kwon T.H. Numerical and experimental investigation of shrinkage behavior of precision injection molded articles. Polymer Eng\& Sci., vol. 48, issue 8, 2008, pp. 1569-1583.

[5] Fisher J.M. Handbook of molded part shrinkage and warpage. 2nd edition, Plastic Design Library, William Andrew, 2013. 292 p.

[6] Kwon K., et al. Theoretical and experimental studies of anisotropic shrinkage in injection moldings of semicrystalline polymers. Polymer Eng.\& Sci., vol. 46, issue 6, 2006, pp. 712-728.

[7] Postawa P. Skurczprzetwórczywyprasek a warunkiwtryskiwania (Shrinkage of moldings and injection molding conditions). Polimery, vol. 50, issue 3, 2005, pp. 201-207. (In Polish).

[8] Gershon A.L., Gyger L.S., Bruck H.A., Gupta S.K. Thermoplastic polymer shrinkage in emerging molding processes. Experimental Mechanics, vol. 48, issue 6, 2008, pp. 789-798.

[9] Slota J., Spišák E., Gajdoš I.: Modern approaches in development of plastic products. Journal for Technology of Plasticity, vol. 34, issue 1-2, 2009, pp. 97-104.

[10] Kowacs J.G., Solymossy B. Effect of glass bead content and diameter on shrinkage and warpage of injection-molded PA6. Polymer Engineering \& Science vol. 49, issue 11, 2009, pp. 2218-2224. 
[11] Shelesh-Nezhad K., Taghizadeh A. Shrinkage behavior and mechanical performances of injection molded polypropylene/talc composites. Polymer Eng.\& Sci., vol. 47, issue 12, 2007, pp. 2124-2128.

[12] Kazmer D.O. Injection mold design engineering. Munich, Carl HanserVerlag, 2007. 444 p.

[13] Malloy R.A. Plastic part design for injection molding. An introduction. 2nd edition, Munich, Carl HanserVerlag, 2010. 549 p.

[14] Wong C.T., Sulaiman S., Ismail N., Hamouda A.M.S. Design and simulation of plastic injection moulding process. Pertanika J. Sci. \& Technol. Supplement, vol. 12, issue 2, 2004, pp. 85-99.

[15] Singh D. A guide to injection moulding technique. Munich, BookRix, 2018. 41 p.

[16] Miatliuk K., Łukaszewicz A., Siemieniako F. Coordination method in design of forming operations of hierarchical solid objects. Proceedings of International Conference on Control, Automation and Systems: ICCAS'2008, Oct. 14-17, 2008, Seoul, South Korea, pp. 2724-2357.

[17] González-Lluch C., et al. A survey on 3D CAD model quality assurance and testing tools, Computer-Aided Design, vol. 83, 2017, pp. 64-79.

[18] Łukaszewicz A., Panas K., Szczebiot R. Design process of technological line to vegetables packaging using CAx tools. Proceedings of 17th International Scientific Conference on Engineering for Rural Development, May 23-25, 2018, Jelgava, Latvia, pp. 871-876

[19] Łukaszewicz A., Skorulski G., Szczebiot R. The main aspects of training in the field of computeraided techniques (CAx) in mechanical engineering, Proceedings of 17th Int. Scientific Conference on Engineering for Rural Development, May 23-25, 2018, Jelgava, Latvia, pp. 865-870.

[20] Sidun P., Łukaszewicz A. Verification of ram-press pipe bending process using elasto-plastic FEM model. ActaMechanica et Automatica, vol. 11, issue 1, 2017, pp. 47-52.

[21] Mieczkowski G. Stress fields and fracture prediction for adhesively bonded bi-material structure with sharp notch located on the interface. Mechanics of Composite Materials, vol. 53, issue 3, 2017, pp. 305-320.

[22] Trochimczuk R., et al. Finite element method stiffness analysis of a novel telemanipulator for minimally invasive surgery. Simulation: Transactions of the Society for Modeling and Simulation International, 2019, (on-line), DOI: 10.1177/0037549719835920.

[23] Łukaszewicz A. Nonlinear numerical model of heat generation in the rotary friction welding. Journal of Friction and Wear, vol. 39, issue 6, 2018, pp. 476-482.

[24] Paimushin V.N., et al. Mechanics of fiber composites: Forms of loss of stability and fracture of test specimens resulting from three-point bending tests. Z Angew Math Mech., vol. 99, issue 1, 2019, e201800063.

[25] Barsukov V.V., et al. Express evaluation method of internal friction parameters in molding material briquettes. Journal of Friction and Wear, Vol. 38, issue 1, 2017, pp. 71-76.

[26] Józwik, J. et al. Industrial robot repeatability testing with high speed camera Phantom v2511. Advances in Science and Technology Research Journal, vol. 10, issue 32, 2016, pp. 86-96.

[27] Grodzki W., Łukaszewicz A. Design and manufacture of unmanned aerial vehicles (UAV) wing structure using composite materials.Mat. $\square$ wiss. u. Werkstofftech, vol. 46, issue 3, 2015, pp. 269-278.

[28] Józwik J., Wac-Włodarczyk A., Michałowska J., Kłoczko M. Monitoring of the noise emitted by machine tools in industrial conditions. J. Ecol. Engineering, vol. 19, issue 1, 2018, pp. 83-93.

[29] Cai J. Technology of data conversion and reconstruction for complex surface based on noncontact measurement, Applied Mechanics and Materials, vol. 685, 2014, pp. 614-617.

[30] Łukaszewicz A., Miatluk K. Reverse engineering approach for object with free-form surfaces using standard surface-solid parametric CAD system. Solid State Phenomena, vols. 147-149, 2009, pp. 706-711.

[31] Hodolic J., Matin I., Stevic M., Vukelic, D. Development of integrated CAD/CAE system of mold design for plastic injection molding.MaterialePlastice,vol. 46, issue 3, 2009, pp. 236-242.

[32] Matin I., et al. Development of CAD/CAE system for mold design. Journal of Production Engineering,vol. 13, issue 1, 2010, pp. 61-64.

[33] Mircheski I., Łukaszewicz A., Szczebiot R. Injection process design for manufacturing of bicycle plastic bottle holder using CAx tools, Procedia Manufacturing, vol. 32, 2019, pp. 68-73.

[34] Mircheski I., et al. Application of CAx system for design and analysis of plastic parts manufactured by injection moulding. Proceedings of 18th International Scientific Conf. on Engineering for Rural Development, May 22-24, 2019, Jelgava, Latvia, pp. 1755-1760. 
[35] Poniatowska M., Werner A. Fitting spatial models of geometric deviations of free-form surfaces determined in coordinate measurements. Metrology and Measurement Systems, vol. 17, issue 4, 2010, pp. 599-610. 